\title{
PRÁTICAS FORMATIVAS DA MEDICINA: MANUAIS DE SAÚDE E A FORMAÇÃO PARA A URBANIDADE
}

\author{
Maria Stephanou*
}

\begin{abstract}
SÍNTESE - O estudo examina manuais de higiene, espécie de guias de saúde, elaborados por médicos gaúchos nos anos 20 e 30 e que tiveram ampla circulação entre a população, especialmente das cidades. Considera-se que constituem meios de formação por excelência e se inscrevem entre os múltiplos processos de constituição do sujeito urbano. Integraram um conjunto de estratégias formativas da medicina dirigidas aos cidadãos com vistas à produção de comportamentcs e atitudes de urbanidade e civilidade. As proposiçőes foucaultianas acerca das "técnicas de si" constituem o aporte teórico da investigação.

PALAVRAS-CHAVE - formação, medicina, urbanidade.
\end{abstract}

\begin{abstract}
The study examines hygiene manuals - a kind of health guide put together by doctors from Rio Grande do Sul in the 1920s and 1930s and which had a broad circulation among people, especially in urban areas. These manuals are considered excellent means of formation, and they are inserted into the multiple processes of constitution of the urban individual. They integrated a set of formative medical strategies directed to the citizen, seeking to produce behaviors and attitudes of urbanity and civility. The propositions of Foucault on the "techniques of the self" constitute the theoretical support of the investigation.

KEY WORDS - formation, medicine, urbanity.
\end{abstract}

Apresento, neste artigo, um estudo ${ }^{1}$ que está inserido numa investigação mais ampla que examina os processos de subjetivação envolvidos em experiências médico-formativas das primeiras décadas deste século, no Rio Grande do Sul. Investigação que busca compreender a importância destas experiências na constituição da subjetividade moderna, fortemente impregnada pelos saberes médicos.

Considerar a complexidade desta subjetividade implica reconhecer os múltiplos agenciamentos que a constituem. Meu objetivo aqui é examinar um

* Historiadora. Professora da Faculdade de Educação da Universidade Federal do Rio Grande do Sul. Pesquisadora do Projeto Integrado, sendo responsável pelo subprojeto "As ações e práticas formativas da medicina social no Rio Grande do Sul", com apoio, em diferentes momentos, do Conselho Nacional de Desenvolvimento Científico e Tecnológico (CNPq), Fundação de Amparo à Pesquisa do Rio Grande do Sul (FAPERGS) e Pró-Reitoria de Pesquisa da Universidade Federal do Rio Grande do SUl (PROPESO/UFRGS).

1 A pesquisa junto às fontes primárias referidas neste artigo contou com a competente colaboração das bolsistas Adriana Pozzebon de Miranda (PIBIC/CNPq/UFRGS) e Marcelisa Monteiro (AP/CNPq). 
destes agenciamentos: a produção e circulação de manuais de higiene, espécie de guias de saúde, elaborados por médicos gaúchos nos anos 20 e 30 e que tiveram ampla circulação entre a população. Considero que se constituem em meios de formação por excelência e se inscrevem entre os múltiplos processos de constituição do sujeito urbano.

Os estudos sobre a importância da medicina na produção da modernidade no Brasil $^{2}$ vêm destacando, a partir de fins do século XIX, a proeminência dos médicos como formuladores de um projeto de civilização à européia para o país, bem como sua atuação no processo de formação dos cidadãos quanto a determinadas atitudes e comportamentos próprios à vida na urbe, notadamente os cuidados com a higiene, as práticas salutares e a polidez das condutas.

Os manuais examinados podem ser inscritos entre as práticas médicas voltadas particularmente à formação dos habitantes das cidades, em especial no intuito de fazer com que cada indivíduo venha prestar atenção em si mesmo, seu asseio, autocuidado, contribuindo ativamente, desde si, na produção de uma verdade acerca de si mesmo. Enfim, práticas nas quais se acentuava a importância dos cuidados individuais e do autogoverno na formação da civilidade e urbanidade que deveriam caracterizar cada cidadão.

\section{As atenções para consigo na formação do cidadão}

O exame dos processos de formação do cidadão nas primeiras décadas deste século tem levado a observar uma crescente importância dos cuidados pessoais ocupações consigo - em relação ao asseio, ao corpo, à saúde física, mental e moral, às regras de conduta e à cortesia, aos rituais da sociabilidade urbana, à intimidade e à sexualidade. Corbin (1991) situa em fins do século XIX um intrincado conjunto de procedimentos privados de atenções sobre si: o uso do espelho, os equipamentos domésticos de higiene individual, a escrita de diários, entre outros, que apontam para o aprofundamento das práticas "narcísicas", de exaltação da idéia de indivíduo em boa medida identificado com os valores de civilidade e urbanidade da cultura ocidental moderna.

No que diz respeito à atuação da medicina nos contextos urbanos emergentes no Brasil na virada do século, também podemos observar uma preocupação acentuada com as práticas individuais. Os saberes médicos abordam intensamente a importância do cultivo da saúde pessoal, não em detrimento da saúde coletiva, mas com um refinamento dos procedimentos que cada pessoa deveria operar sobre si mesma para manter-se sadia e asseada. Afinal, nos discursos da época é recorrente a idéia de que "o fenômeno coletivo é reflexo das condições individuais" (Espírito, 1934, p. 5).

Embora reduzindo uma problemática abrangente, circunscrevi esta exposição ao exame dos processos de subjetivação sob a ótica das "técnicas de si" teorizadas por Foucault, tomando-as enquanto operadores analíticos que possibilitam acercar-se do "como" foi se produzindo determinada subjetividade (in)formada pelos saberes médicos. Saberes que, intimamente associados com o asseio, o

2 Veja-se a respeito Herschmann, Pereira (1994); Herschmann, Kropf, Nunes (1996), entre outros. 
autocuidado, a autodisciplina, a preservação da saúde individual, constituíram uma espécie daquilo que Foucault denominou "técnicas de si", no sentido de

"procedimentos [...] pressupostos ou prescritos aos individuos, para fixar sua identidade, mantê-la ou transformá-la em função de um certo número de fins, e isso graças às relações de domínio de si sobre si ou de conhecimento de si por si" (Curso 1980/81, Foucault, 1997, p. 109, grifo nosso).

As atenções consigo supõem atitudes, maneiras de se comportar que são refletidas, aperfeiçoadas, ensinadas (Foucault, 1985, p. 50).

A análise dos manuais de higiene e civilidade nesta investigação está pautada pelo suposto da crescente importância da medicina na elaboração, prescrição e difusão de uma extensa pauta de comportamentos de urbanidade, de "técnicas de si", por meio da circulação de saberes sobre o corpo, a sexualidade, as doenças, as atenções pessoais visando a higiene e saúde. A disseminação destes conhecimentos junto à população ilustram o intuito de "informar para formar" explicitado pelas práticas médicas. Em suma, saberes novos que possibilitaram novas experiências subjetivas. Para o Dr. Felicissimo Difini

\footnotetext{
"assim como é necessário o preparo prévio das terras para que as sementes aí lançadas se desenvolvam dando os melhores resultados, da mesma forma, em se tratando de saúde pública, não será completo o resultado conseguido se o povo não estiver preparado para compreender a razão de ser das medidas e conselhos emanados dos responsáveis pela saúde coletiva, e aceitá-los, colaborando, assim, de forma eficiente, no sentido de se obter o maior aproveitamento possivel" (1943, p. 154).
}

Em sua reflexão, o Dr. Difini reconhece os benefícios dos hospitais, casas de saúde e dispensários no que tange à preservação e recuperação da saúde, contudo insiste que

"não se verificará a eficiência desejada se não houver uma consciência sanitária, porque sendo a saúde um problema sobretudo individual, é indispensável que cada um a tenha como sua principal preocupação. E quem zelar pela própria saúde estará cooperando para o bem geral, pois os indivíduos sãos constituirão uma coletividade sã" (Id., grifos meus).

Zelar pela própria saúde, como principal preocupação de cada um era a recomendação, mas também um dever. Observe-se que cuidados pessoais cada vez mais interiorizados e, simultaneamente, cada vez mais explicitados, irão compor a higiene e a saúde contemporâneas (Vigarello, 1988, p. 175).

\section{Os manuais de saúde e higiene: formar para a urbanidade}

Há convergência, entre os médicos da época, quanto à necessidade de levar os indivíduos a serem agentes de sua própria saúde, conduzidos pelo esclarecimento da medicina. Seus discursos matizam com diferentes intensidades o que concebem como ameaças advindas do crescimento das cidades, dos novos processos de trabalho e dos desequilíbrios sociais que proliferavam por toda parte. Para os médicos, contudo, havia muitos obstáculos a enfrentar, sobressaindo-se a ignorância do povo e sua degradação moral e mental. Daí a urgência da formação sanitária, destacando-se a difusão de manuais de higiene e boas regras de condu- 
ta, produzidos pelos médicos, em linguagem clara e acessivel à população em geral a quem se dirigiam.

Examino dois manuais produzidos na década de 30, ambos de autoria do médico gaúcho Dr. Mário Totta e que, devido à significativa disseminação no Rio Grande do Sul, tiveram muitas reedições, podendo ser tomados como paradigmáticos nesta análise. Um foi denominado Breviário da saúde: medicina em pílulas, o outro intitulado $O$ médico em casa, ambos publicados pela Livraria do Globo de Porto Alegre. Apesar dos títulos sugerirem matéria de caráter estritamente médico, procuro demonstrar que eles constituíram meios de formação com vistas a comportamentos e condutas de civilidade.

No pequeno manual Breviário da saúde, o Dr. Totta elenca cuidados, procedimentos e atenções a serem adotados na vida cotidiana. Numa espécie de diálogo com os leitores, são apresentados pequenos textos, quase sob a forma de ditados populares, em que informalmente o médico divulga conselhos. São as pilulas a que alude o título. Pequenas drágeas, ou melhor, pequenos conselhos de grande alcance. Algumas situações são apresentadas de forma quase bizarra, outras insistem num minucioso detalhamento da rotina diária, incluindo os cuidados com o corpo - dentes, cabelos, olhos, etc. - cuidados com a alimentação, o vestuário, as regras de polidez das condutas, o uso do cigarro, do álcool, controle dos vícios, até provérbios que ilustram as atitudes sugeridas. $O$ tom imperativo e essencialmente prático caracterizam a forma deste discurso médico.

$\mathrm{Na}$ introdução do manual, já se esboça a conversa direta com o leitor, uma espécie de interlocução onde abunda o tom imperativo em expressões: pensa, repara, segue, toma juízo, que se somam a uma série de normatizações. Aliás, todo o Breviário está composto por pequenos tópicos prescritivos: fazer, não fazer, evitar, ocupar-se consigo, aconselhar-se com seu médico. ${ }^{3}$

Há um conjunto de argumentos visando o convencimento dos leitores e sua adesão sincera, como no texto da introdução do manual:

\begin{abstract}
"Eu bem sei que algumas destas pílulas [conselhos] são amargas... Eu bem sei... Há conselhos que embora cristalinamente bem intencionados irritam sempre porque entendem de corrigir hábitos inveterados. Mas tem paciência, leitor querido. No fim das contas o amargor se transformará em dulçor pelo benefício proporcionado e colhido. E agradecerás. Não faças cara feia e vai engolindo as pílulas [conselhos]. Elas são manipuladas para teu regalo e para teu proveito. Vai engolindo, de cara alegre... e com fé" (Totta, 1939a, p. 3).
\end{abstract}

Os dois manuais se aproximam. O Breviário é uma espécie de versão em linguagem ainda mais acessivel. Na obra intitulada O médico em casa o Dr. Mário Totta era enfático: "este livro é sentinela da saúde", não se tratando, pois, de um guia de procedimentos terapêuticos, mas objetivando a difusão, em estilo singelo, de boas regras de higiene preventiva, aspirando apenas a um prêmio: o de ser benéfico (1939b, p. 7).

3 Quando precisares de uma fatiota, vai ao alfaiate; quando necessitares de conserto no telhado, chama o pedreiro. Mas, quando estiveres doente, procura o médico. Não ouças, sobre a moiéstia que te aflige, o teu engraxate. Salvo se estiveres desenganado da cura e quiseres levar, no dia do teu enterro, os sapatos bem lustrosos (Totta, 1939a, p. 13). 
Em que consistia tal benefício? Para a realização deste ideal de boa vontade, não bastava que o livro fosse somente lido (grifos do autor): era necessário, acima de tudo, que fossem atendidas as regras de conduta que ele gostosamente transmitia (Idem, p. 8). Em pequenos capítulos, o autor percorria situações quotidianas, tanto relativas à saúde quanto aos comportamentos asseados e polidos, com conselhos minuciosos e as devidas explicações médicas.

Embora possamos constatar a presença de temas mais ligados à terapêutica, proliferam os temas voltados às regras de boa conduta e urbanidade, tais como: abusos à mesa, higiene do nariz, olhos e boca, hábito de visitar, o uso do cigarro, a genuflexão e o lenço, banhos de sol, serra ou mar, a mania de emagrecer, os esportes desregrados em geral e o futebol em particular, entre outros. Estes eram dirigidos não só à gente simples, mas também àqueles "que se jactam de uma educação esmerada" (Id., p. 77), mas se esquecem freqüentemente de princípios comezinhos de civilidade, como o hábito de lavar as mãos antes das refeições, o uso de guardanapos, não fumar nas alcovas, etc. Para o Dr. Totta

\footnotetext{
"desde o mais obscuro trabalhador, que leva a maior parte do seu dia manuseando instrumentos desasseados, até o burocrata por cujas mãos passam papéis de várias procedências, todos nós, quaisquer que sejam a profissão e os hábitos de vida, devemos ter sempre as mãos num estado de limpeza tão esmerada quanto possivel" (Id. p. 107).
}

Além disso, o autor argumentava a importância deste hábito tão elementar, qual seja da lavagem das mãos, como atributo indiscutível de urbanidade. É esta mesma expressão que ele emprega em seu discurso:

"[...] pelos nossos hábitos de urbanidade, o aperto de mão é mais do que um uso e nós apertamos indiferentemente, e com a mesma expansibilidade, a mão de um homem sadio ou a de um tuberculoso [...]. A higiene cuidadosa das mãos e, muito principalmente, a lavagem delas antes das refeições, deve constituir para todos uma obrigação imperiosa; os que cumprem essa obrigação tornam-se os guardas vigilantes da sua própria saúde, o que vale dizer os guardas do seu maior tesouro. Além de que, é preciso não olvidar jamais, e este preceito deve ser incutido desde cedo no espirito das crianças, que o asseio corporal é o reflexo da educação e - para usar a expressão de um higienista notável - uma das manifestações da dignidade" (Id., p. 80-81, grifos meus).

Lado a lado com orientações de profilaxia, primeiros socorros e práticas curativas domésticas, os manuais fizeram circular diferentes saberes, inúmeras orientações associadas ao refinamento dos comportamentos demandađos pela vida urbana. Comportamentos que se expressam tanto no autocuidado, quanto nas atenções com a aparência e a visibilidade pública. Estes saberes, indiscutivelmente, estiveram presentes em outras iniciativas de formação do cidadão, embora com um acento surpreendente nas práticas médico-educativas.

\section{Conchindo}

Para finalizar essa pequena incursão pelos guias de higiene e saúde concebidos como meios de formação do cidadão, procurei apresentar construções discursivas que podem ser associadas às práticas que deveriam contribuir para constituir, desenvolver, modificar as condutas, o caráter, as ações do individuo, ligando-as sempre a um governo de si por si. 
Como ressaltei, há uma afluência discursiva que se ocupa em convencer os indivíduos, difundindo saberes, falando-lhes diretamente sobre situações quotidianas e boas condutas a perseguir. Os manuais de higiene constituíram-se em dispositivos fundamentais para a formação de cidadãos sadios e valiosos à sociedade. Mais do que imposições, os manuais examinados representaram textos de consulta informal, espontânea, cujo valor de verdade está atestado pela condição de médico dé seu autor e pelo caráter de "civilidade" ou de modernidade que sugerem. O tom ameaçador de alguns exemplos, os perigos referidos, as vantagens argumentadas junto às medidas salutares aconselhadas dão conta do convencimento almejado, ou ainda, da possibilidade de internalização de um conjunto de exigências de urbanidade. Propiciam, assim, novas formas de subjetivação, experiências em que os cuidados de si para si tiveram proeminência, particularmente a partir de fins do século XIX.

\section{Referências bibliográficas}

CORBIN, Alain. "O segredo do individuo". In: História da vida privada, 4: da Revolução Francesa à Primeira Guerra. Michelle Perrot (dir.). São Paulo: Cia. das Letras, 1991, p. 419-501.

DIFINI, Felicíssimo. "Formação da consciência sanitária no Rio Grande do Sul". In: Panteão médico rio-grandense. Sintese cultural e histórica, progresso e evolução da medicina no Rio Grande do Sul. 1943. Porto Alegre: Ramos, Franco, 1943, p. 154-155.

ESPÍRTTO, Poli Marcelino. Contribuição para a higiene escolar no Estado do Rio Grande do Sul. Tese apresentada à Faculdade de Medicina de Porto Alegre em $1^{\circ}$ de março de 1934. Porto Alegre: Globo, 1934.

FOUCAULT, Michel. História da sexualidade II: O uso dos prazeres. Rio de Janeiro, Graal, 1990a. 6. ed.

- História da sexualidade III: O cuidado de si. 1. ed. Rio de Janeiro: Graal, 1985.

. Resumo dos cursos do Collège de France (1970-1982). trad. Andréa Daher. Rio de Janeiro: Jorge Zahar, 1997.

HERSCHMANN, M., PEREIRA, Carlos A. M.(org.). A invenção do Brasil moderno: medicina, educação e engenharia nos anos 20-30. Rio de Janeiro: Rocco, 1994.

HERSCHMANN, M, KROPF, S., NUNES, C. Missionários do progresso: médicos, engenheiros e educadores no Rio de Janeiro (1870-1937). Rio de Janeiro: Diadorim, 1996.

STEPHANOU, Maria. "Uma forma de formação: médicos na escola profissional". Veritas, Porto Alegre, v. 42, n. 2, jun. 1997a, p. 291-306.

___ . "Práticas educativas da medicina social: os médicos se fazem educadores". In: História da Educação/ASPHE. Pelotas, Ed. da UFPel, v. 1, n. 2, set. 1997b, p. 145-168.

TOTTA, Mário. Aos médicos. (Discurso proferido à classe médica em 31 de dezembro de 1936). Obras, conferências, crônicas, contos, cartas e bilhetes, discursos e memónias. Porto Alegre: Selbach, 1952.

- Breviário da saúde: medicina em pílulas. Porto Alegre: Globo, 1939a.

O médico em casa. Porto Alegre: Globo, 1939b.

VIGARELLO, Georges. O limpo e o sujo: a higiene do corpo desde a Idade Média. Lisboa: Editorial Fragmentos, 1988. 